\title{
PENGARUH DESAIN PRODUK DAN PROMOSI TERHADAP VOLUME PENJUALAN DIVISI PROCTER \& GAMBLE PADA PT BORWITA CITRA PRIMA DI DENPASAR
}

\author{
Ni Made Vina Yanti ${ }^{1}$ \\ Nyoman Dwika Ayu Amrita ${ }^{2}$ \\ ${ }^{1,2}$ Fakultas Ekonomi Universitas Ngurah Rai, Bali, Indonesia \\ 1e-mail : Devinayanti24@gmail.com
}

\begin{abstract}
ABSTRAK
Pemasaran merupakan salah satu dari kegiatan pokok yang dilakukan oleh para pebisnis dalam upaya untuk mempertahankan kelangsungan perkembangan dan perluasan usahanya. Pemasaran posisinya berada antara produsen dan konsumen, artinya pemasaran merupakan alat penghubung antara produsen dan konsumen. Masalah desain dari suatu produk telah menjadi salah satu faktor yang perlu mendapatkan perhatian serius dari manajemen khususnya team pengembangan produk baru, karena sasaran konsumen yang dituju tidak sedikit yang mulai mempersoalkan masalah desain suatu produk yang mampu memenuhi kebutuhan dan keinginan konsumen. Penelitian ini dilakukan pada PT.Borwita Citra Prima di Denpasar dengan judul "Pengaruh Desain Produk dan Promosi Terhadap Volume Penjualan Divisi Procter \& Gamble pada PT.Borwita Citra Prima di Denpasar".

Pada penelitian ini yang menjadi objek penelitian adalah desain produk, promosi, dan volume penjualan adapun Teknik pengumpulan data melalui observasi, wawancara, kuisioner dan studi dokumentasi . Teknik analisis data yang digunakan pada penelitian ini yaitu uji validitas, uji reliabilitas,uji asumsi klasik, analisis regresi linier berganda, analisis determinasi, uji t-test, dan uji f-test. Berdasarkan hasil analisis bahwa terdapat pengaruh positif dan signifikan secara parsial dan simultan antara desain produk dan promosi terhadap volume penjualan divisi $P \& G$ pada PT.Borwita Citra Prima di Denpasar.
\end{abstract}

Kata kunci : Pemasaran,Desain Produk, Promosi, Volume Penjualan

\begin{abstract}
Marketing is one of the main activities carried out by business people in an effort to maintain the continuity of the development and expansion of its business. The design problem of a product has become one of the factors that need to get serious attention from management, especially the new product development team, because the targeted consumers are not a few who begin to question the design problem of a product that is able to meet the needs and desires of consumers. This research was conducted at PT. Borwita Citra Prima in Denpasar with the title "The Effect of Product Design and Promotion on Procter \& Gamble Division Sales Volume at PT. Borwita Citra Prima in Denpasar".In this study, the object of research is product design, promotion, and sales volume while the technique of collecting data through observation, interviews, questionnaires and documentation studies. Data analysis techniques used in this study are validity test, reliability test, classic assumption test, multiple linear regression analysis, analysis of determination, t-test, and f-test. Based on the results of the analysis that there is a partial and simultaneous positive and significant influence between product design and promotion on the sales volume of the P \& G division at PT. Borwita Citra Prima in Denpasar.
\end{abstract}

Keywords: Marketing, Product Design, Promotion, Sales Volume 


\section{PENDAHULUAN}

Pemasaran merupakan salah satu dari kegiatan pokok yang dilakukan oleh para pebisnis dalam upaya untuk mempertahankan kelangsungan perkembangan dan perluasan usahanya. Pemasaran posisinya berada antara produsen dan konsumen, artinya pemasaran merupakan alat penghubung antara produsen dan konsumen. Melihat perkembangan perekonomian seperti sekarang ini tanpa adanya kegiatan pemasaran yang efektif dalam menunjang usaha perusahaan maka mungkin tujuan yang ingin dicapai yaitu laba yang maksimal akan sangat sulit, sehingga dapat dikatakan berhasil tidaknya dalam pencapaian tujuan bisnis tergantung pada keahlian manajemen perusahaan dalam bidang pemasaran.

Masalah desain dari suatu produk telah menjadi salah satu faktor yang perlu mendapatkan perhatian serius dari manajemen khususnya team pengembangan produk baru, karena sasaran konsumen yang dituju tidak sedikit yang mulai mempersoalkan masalah desain suatu produk yang mampu memenuhi kebutuhan dan keinginan konsumen. Hal ini penampilan dan fungsi suatu produk dalam memenuhi kebutuhan pelanggan. (Angipora, 2002 dalam Pradana, 2010).

Selain desain produk yang baik, dalam pemasaran juga tidak bisa diabaikan pada aspek promosi. Melalui komunikasi yang efektif di dalam toko dan program promosi, hal ini akan mempengaruhi pilihan merek yang dibeli konsumen dan mendorong keputusan untuk belanja lebih banyak. Promosi penjualan (sales promotion) merupakan salah satu elemen dari marketing mix menjadi sangat penting. Menurut Aruman (2007 : 20-21), anggaran iklan dan promosi penjualan 70 : 30, kini berbalik menjadi 30 : 70 . Dengan kata lain promosi penjualan mempunyai dampak terhadap penjualan. Hal Ini dikarenakan oleh perilaku konsumen yang pertama kali sangatlah sensitif terhadap harga namun tetap mementingkan kualitas. Kedua,tidak menyukai suatu kelebihan yang sifatnya sama. Mereka ingin sesuatu yang lebih baik dan berbeda. Ketiga, kebutuhannya bergeser dari hal-hal yang kelihatan nyata ke sesuatu yang sifatnya tidak kasat mata. Mereka selalu menginginkan sesuatu yang eksperimental. Maka dari itu perusahaan PT. Borwita Citra Prima merupahan Perusahaan Distributor tunggal di Bali khusus cabang Denpasar yang mendistribusikan produk $P \& G$ dengan Brand Merk seperti Pantene, Head \& Shoulders, Rejoice, Downy, Gillette, Olay, Oral-b, Pampers, Vicks, dan Whisper ini selalu memperhitungkan serta mengutamakan desain produk serta promosi untuk meningkatkan volume penjualan dari perusahaan. PT.Borwita Citra Prima di Denpasar tidak mencapai target selama 2 tahun terakhir yakni dari tahun 2017-2018. Hal tersebut perlu mendapatkan perhatian serius oleh manajemen perusahaan. Permasalahan yang terjadi dengan PT. Borwita Citra Prima tak lepas dari desain produk dan promosi terhadap volume penjualan.

Penelitian ini bertujuan untuk mengetahui pengaruh secara parsial desain produk dan promosi terhadap volume penjualan dan perngaruh secara simultan desain produk dan promosi terhadap volume penjualan divisi $P \& G$ pada PT. Borwita Citra Prima di Denpasar.

\section{METODE PENELITIAN}

Desain penelitian ini termasuk dalam penelitian kuantitatif. Populasi dalam penelitian ini adalah sebanyak 150 pelanggan toko. Dalam penelitian ini meggunakan metode purposive sampling dengan Sampel yang diambil adalah hasil sampel sebanyak 60 Pelanggan Toko. Sampling purposive merupakan teknik penentuan sampel dengan pertimbangan tertentu yang bertujuan untuk memperoleh satuan sampling yang memiliki karakteristik atau kriteria yang dikehendaki dalam pengambilan sampel (Sugiyono, 2011). Teknik pengumpulan data dalam penelitian ini dilakukan dengan observasi, wawancara, Studi dokumentasi, Kuisioner. Setiap jawaban kuisioner mempunyai bobot atau 
skor nilai dengan skala likert sebagai berikut: STS $($ sangat tidak setuju $)=$ skor 1 , TS $($ tidak setuju $)=$ skor 2, CS (cukup setuju) $=$ skor $3, \mathrm{~S}($ setuju $)=$ skor $4, \mathrm{SS}$ (sngat setuju $)=$ skor 5 . Teknik analisis data dalam penelitian ini menggunakan uji validitas, uji reliabilitas, Analisis Regresi Linier Berganda, Analisis Determinasi $\left(\mathrm{R}^{2}\right)$, Analisis t-test, Analisis F-test.

\begin{abstract}
HASIL DAN PEMBAHASAN Uji Validitas

Uji Validitas digunakan untuk mengetahui sah/valid tidak suatu kuisioner, suatu kuisioner dinyatakan valid jika pertanyaan pada kuisioner mampu mengungkapkan sesuatu yang akan diukur oleh kuisioner tersebut (Imam Ghozali 2001:142).
\end{abstract}

Tabel 1

Hasil Uji Validitas

Case Processing Summary

\begin{tabular}{|c|c|c|c|}
\hline & & $\mathrm{N}$ & $\%$ \\
\hline & Valid & 60 & 100.0 \\
\hline Cases & Excluded $^{\mathrm{a}}$ & 0 & .0 \\
\hline & Total & 60 & 100.0 \\
\hline
\end{tabular}

Sumber: Pengolahan Data Penelitian Pada Lampiran

a. Listwise deletion based on all

variables in the procedure.

Berdasarkan hasil uji instrument denga penyebaran kuesioner pada 60 responden maka seperti pada tabel 4.10 , dapat dilihat bahwa seluruh indikator variable pada penelitian ini yaitu desain produk, promosi dan volume penjualan valid karena memiliki nilai koefisien korelasi lebih dari 0,30.

\section{Uji Reliabilitas}

Uji reliabilitas bertujuan untuk mengetahui keandalan alat ukur atau untuk mengetahui konsistensi alat ukur jika digunakan untuk mengukur obyek yang sama lebih dari sekali. Uji reliabilitas yang digunakan dalam penelitian ini adalah dengan metode Alpha Cronbach. Nilai batas (cutof point) yang diterima untuk tingkat Alpha Cronbach adalah $\geq 0,60$ walaupun ini bukan merupakan standar absolut oleh Uma Sekaran (2000). Hasil uji menunjukkan nilai cronbach alpha sebagai berikut. 
Tabel 2

Hasil Uji Reliabilitas

Reliability Statistics

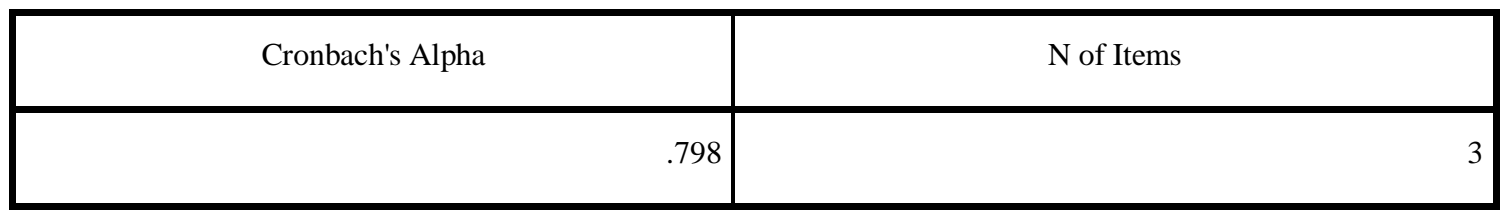

Sumber: Pengolahan Data Penelitian Pada Lampiran

\section{Uji Asumsi Klasik}

\section{Uji Normalitas}

Uji normalitas pada penelitian ini dilakukan dengan menggunakan uji Komogorov-
Smirnov di mana data yang berdistribusi normal jika Asymp. Sig (2-tailed) lebih besar dari $0.1(\alpha=0,05 \%)$. Berdasarkan hasil uji SPSS 20.0 For Windows dapat dilihat sebagai berikut :

Tabel 3

Hasil Uji Normalitas

\begin{tabular}{|c|c|c|}
\hline & & $\begin{array}{c}\text { Unstandardized } \\
\text { Residual }\end{array}$ \\
\hline \multicolumn{2}{|l|}{$\mathbf{N}$} & 60 \\
\hline \multirow{2}{*}{$\begin{array}{l}\text { Normal } \\
\text { Parameters }\end{array}$} & Mean & $.0 O O O O O O$ \\
\hline & Std. & .72214849 \\
\hline \multirow{3}{*}{$\begin{array}{l}\text { Most Extreme } \\
\text { Differences }\end{array}$} & $\begin{array}{l}\text { Deviation } \\
\text { Absolute }\end{array}$ & .200 \\
\hline & Positive & .180 \\
\hline & Negative & -.200 \\
\hline \multicolumn{2}{|c|}{ Kolmogorov-Smirnov $Z$} & 1.547 \\
\hline \multicolumn{2}{|c|}{ Asymp. Sig. (2-tailed) } & .117 \\
\hline
\end{tabular}

Test distribution is Normal

b. Calculated from data.

Sumber: Pengolahan Data Penelitian Pada Lampiran

Berdasarkan tabel 3 diatas diketahui nilai Asymp Sig (2-tailed) $=0,117$ lebih besar dari 0,05 , maka model regresi memenuhi asumsi normalitas dan data berdistribusi normal.

\section{Uji Heteroskedastisitas}

Model regresi yang baik adalah yang homokedastisitas atau tidak terjadi heterokedastisitas. Pengujian masalah heterokedastisitas dalam model regresi dilakukan dengan menggunakan uji statistik berupa uji Glejser, berikut hasil uji heteroskedastisitas dapat dilihat pada tabel berikut : 
Tabel 4

Hasil Uji Autokorelasi

\begin{tabular}{|c|c|c|c|c|c|}
\hline & & & ents ${ }^{a}$ & & \\
\hline \multirow[b]{2}{*}{ Model } & \multicolumn{2}{|c|}{$\begin{array}{c}\text { Unstandardized } \\
\text { Coefficients }\end{array}$} & \multirow{2}{*}{$\begin{array}{c}\begin{array}{c}\text { Standardized } \\
\text { Coefficients }\end{array} \\
\text { Beta }\end{array}$} & \multirow[b]{2}{*}{$\mathrm{t}$} & \multirow[b]{2}{*}{ Sig. } \\
\hline & $\mathrm{B}$ & Std. Error & & & \\
\hline 1 (Constant) & $9.095 \mathrm{E}-16$ & 1.170 & & .000 & 1.000 \\
\hline Desain Produk & 0.000 & .056 & 0.000 & 0.000 & 1.000 \\
\hline Promosi & 0.000 & .045 & 0.000 & 0.000 & 1.000 \\
\hline
\end{tabular}

a. Dependent Variable: Unstandardized Residual

Sumber: Pengolahan Data Penelitian Pada Lampiran

\section{Uji multikolinearitas}

Uji multikolinearitas digunakan pada analisis linier berganda karena variabel independennya lebih dari satu dalam satu model regresi.

\section{Uji Analisis Linier Berganda}

Analisis regresi linier berganda digunakan untuk mengetahui untuk mengetahui atau memperoleh gambaran mengenai pengaruh variabel bebas terhadap variabel terikat dengan menggunakan Statistical Package for Social Science (SPSS). Berikut hasil analisis regresi linier berganda :

\section{Analisis Regresi Linier Berganda}

Hasil analisis regresi linier berganda dapat dilihat pada Tabel 5 .

Tabel 5

Rangkuman hasil analisis SPSS version 20.0 for windows variable Desain Produk dan Promosi terhadap Volume Penjualan pada PT.Borwita Citra Prima di Denpasar

\begin{tabular}{|l|c|c|c|}
\hline \multicolumn{1}{|c|}{ Model } & Regresi & t- hitung & Sig. \\
\hline Konstanta & $-2,467$ & $-2,109$ & 0,039 \\
$\begin{array}{l}\text { Desain Produk } \\
\text { (X1) }\end{array}$ & .608 & 10,881 & 000 \\
Promosi (X2) & .185 & 4,087 & \\
$\mathrm{n}=60$ & & & \\
$\mathrm{R}=.864$ & & & \\
$\mathrm{R}^{2}=.755$ & & & \\
Fhitung $=87,886$ & & & \\
\hline
\end{tabular}

Sumber : Lampiran 5 (Data Primer Diolah) 


\section{Analisis determinasi}

Analisis determinasi digunakan untuk mengetahui besarnya kontribusi atau sumbangan perubahan dua atau lebih variabel independen terhadap perubahan variabel dependen. Hasil uji analisis determinasi $\left(\mathrm{R}^{2}\right)$ dapat dilihat pada tabel 4.15.

Berdasarkan hasil pengujian uji analisis determinasi pada tabel 4.15 menjelaskan bahwa besarnya kontribusi/sumbangan desain produk dan promosi terhadap volume penjualan adalah sebesar $75,5 \%$ sedangkan sisanya sebesar $24,5 \%$ dijelaskan oleh variabel lain yang tidak dibahas dalam penelitian ini.

\section{Analisis Statistik Uji t-test}

Analisis Uji t (t-test) digunakan untuk melakukan pengujian terhadap koefisien regresi secara parsial. Pengujian ini

\section{PENUTUP}

\section{KESIMPULAN}

Berdasarkan hasil analisis maka dapat disimpulkan sebagai berikut:

a. Desain produk dan promosi berpengaruh positif dan signifikan secara parsial terhadap volume penjualan. Hal ini dibuktikan oleh nilai $\mathbf{t}_{\text {1hitung }}(10,881), t_{2 \text { hitung }}(4,087)$ $>\mathbf{t}_{\text {tabel }}(1,672)$.

b. Desain produk dan promosi berpengaruh positif dan signifikan secara simultan terhadap volume penjualan. Hal ini dibuktikan oleh nilai $F_{\text {hitung }}(87,886)>$ dari $F_{\text {tabel }}$ $(2,398)$.

\section{SARAN-SARAN}

Penulis memiliki beberapa saran untuk PT. Borwita Citra Prima di Denpasar khususnya divisi $P \& G$ hendaknya desain produk harus lebih banyak variasi dan inovasi untuk menarik konsumen. Begitu juga untuk promosi hendaknya lebih gencar dilakukan baik melalui media massa maupun social media agar masyarakat luas semakin banyak yang mengetahui dengan hal dilakukan untuk mengetahui signifikansi pengaruh secara parsial antara variabel independen terhadap variabel dependen dengan mengasumsikan bahwa variabel independen lain dianggap konstan. Uji ini dalam penelitian digunakan untuk menguji signifikansi koefisien regresi, sehingga diketahui pengaruh secara parsial antara desain produk dan promosi terhadap volume penjualan adalah pengaruh yang positif dan signifikan atau hanya diperoleh secara kebetulan. Hasil uji analisis $\mathrm{t}(\mathrm{t}$-test) dapat dilihat pada tabel 4.15.

\section{Analisis Statistik F-test}

Analisis statistik uji f-test digunakan untuk menguji signifikansi pengaruh variable desain produk dan promosi secara simultan terhadap volume penjualan adalah signifikan atau diperoleh secara kebetulan saja. Hasil uji $\mathrm{F}$ (F-test) dapat dilihat pada tabel 4.15. demikian volume penjualan akan semakin meningkat.

\section{DAFTAR PUSTAKA}

Angipora Marius P, (2002). DasarDasar Pemasaran, PT. Raja Grafindo Persada, Jakarta.

Aruman, (2007) , Sebuah Dunia (Tanpa?) Promosi Penjualan, Majalah MIX, 4:20-. 32.

Cummins, Jullian dan Mullin, Roddy. (2004). Sales Promotion. Jakarta: Penerbit PPM.

Echols, John M. (2005). Kamus Inggris Indonesia, Jakarta: PT. Gramedia Pustaka Utama.

Ghozali, I. (2001). Analisis Multivanate dengan program SPSS. Edisi ke 2. universitas. Diponegoro.

Ghozali, Imam. (2005). Aplikasi Analisis Multivariate dengan program SPSS, Badan. Penerbit Universitas Diponegoro, Semarang. 
Gujarati, Damodar (2003), Econometric, Erlangga, Jakarta.

Hadi, Y. Sumandiyo, (2006). AspekAspek Dasar Koreografi Kelompok, Yogyakarta, Mantili.

Indriantoro, Nur, Bambang Supomo, (2002). Metode Penelitian Bisnis: Untuk Akuntansi dan. Manajemen. Edisi Pertama. BDFE, Yogyakarta.

Kismono Gugup (2001), Pemasaran. Penerbit Andy . Yogyakarta

Kotler,Philip. (2005). Marketing Management Analysis, Planning, Implementation and Control, Ninth Edition. Prentice Hall International, Northwestern University, New Jersey.

Kotler, Philip dan Gary Armstrong. (2001). Principles of Marketing. Pearson Prentice Hall. America

Kotler, Philip. Kevin Lane Keller. (2006). Marketing Management. Prentice Hall International, Northwestern University, New Jersey.

Koentjaraningrat. (1980). Manusia dan Agama. Jakarta: PT. Gramedia.

Lovelock, Christopher. (2004). Service Marketing and Management. New Jersey:Prentice Hall

Marbun, B. N. 2003. Kamus Manajemen. Jakarta: Pustaka Sinar Harapan.

Pradana, Adhitya, (2010), Analisis Pengaruh Harga, Kualitas, Produk, Desain Produk dan Promosi terhadap Keputusan Pembelian Mobil, Toyota,
Skripsi. Universitas Diponegoro, Semarang.

Pakpahan, Efendi, (2009). Volume Penjualan, Jakarta: PT. Bina Intitama Sejahtera.

Rangkut Freddy (2009). Metode Penelitian Bisnis, Metode Penelitian Bisnis: Untuk Akuntansi dan. Manajemen. Edisi Pertama. BDFE, Yogyakarta.

Sugiyono, (2011).Memahami Penelitian Kualitatif. Bandung: ALFABET.

Swastha DH Basu. (2004). Azas-azas Marketing. Yogyakarta: Liberty

Tjiptono Fandy. (2001). Strategi Pemasaran. Penerbit Andy . Yogyakarta

Tjiptono, Fandy dan Gregorius Chandra, (2012). Pemasaran Strategik Yogyakarta, Andi. 